Teaching \& Learning (2018), 12(1), 32-57

\title{
Behind the Scenes: Children's Book Publishing Assemblages and Social (Inter)actions
}

\author{
KARI-LYNN WINTERS \\ Brock University
}

\begin{abstract}
Authorship is both a product and a process. This article uses an Authorship as Assemblage Model (that I developed-Winters, 2010) to investigate the behindthe-scenes collaborative authorship of the picturebook Jeffrey and Sloth (2007). Specifically, using narrative recount and interview transcripts, I will demonstrate how Ben (illustrator), Maggie (editor), and I (author) assembled modes and semiotic resources, while continually shifting among the social (inter)actions of designing, negotiating, producing, and disseminating as we interpreted and realized multimodal meanings in the book.
\end{abstract}

\section{Authorship as Author: Kari-Lynn Winters’ narrative recount}

I start with a spark of an idea, nothing that would be sensible to anyone else - an image, a feeling, a phrase. Jeffrey and Sloth grew out of a feeling of frustration. I was taking a course at UBC in writing with Dr. Carl Leggo in 2003. I was annoyed at myself, because like some writers, I was experiencing writer's block. When I mentioned this problem to Dr. Leggo he facilitated a class discussion. During this discussion another student made a joke about writing, saying that he simply writes about the items in his room, such as his desk, his chair, etc. Dr. Leggo chuckled and said something along the lines of: "Right, if you can't think of anything to write about, write about having nothing to write about" (class notes, 2003). I went home that evening, determined to write about nothing in particular.

That night, I sat down at my computer and wrote,

"I can't think of anything. I can't think of anything to write.

I just can't think of what to write about."

Then I wrote,

"said Jeffrey." 
This ignited an idea — I could write about a kid who was experiencing writer's block!

From here, I made a list of all the things (that I could remember) that people in my life had said about me as a writer. Words like lousy and lazy emerged alongside words like imaginative and storyteller. At this point in time, I felt stuck again as if the writer's block had returned. I knew that I had the beginnings of a story: a character with a goal. I also knew that the setting had to be in the home as I remember sitting at the kitchen table for hours as a child, trying to complete my own homework. But beyond this, I was confused.

I remember thinking, How do I get at the heart of this story? and What might my obstacles be? I put the story aside, half convinced that I was indeed a lousy writer. However, the other half of my mind was fighting back - standing up for me. It kept saying, You're not a lousy writer, you just can't think of anything to write about.

I eventually decided to take another piece of advice from Dr. Leggo. He told our class to "live poetically" and pay attention to the world around us. I did this, gathering snippets of conversations. It was the following Saturday that I decided to go to the Vancouver Aquarium with my son, where we saw a sleepy sloth. I couldn't help but compare myself to him, reiterating the words in my head, lazy. This sparked another idea. Perhaps this sloth could be a match for Jeffrey!

From there, it felt as if the story wrote itself. I remember writing it as quickly as I could when I got home - I didn't want to forget. I also remember experiencing lucid moments of characterization (Sloth would want to sleep, therefore he would want items that would help him sleep more comfortably like a pillow and a blanket) and plot (Sloth could be a doodle that comes to life and Jeffrey could be in control of him). When I was finished that day, I had a so-so chunk of a story that might work.

During the edits over the next few weeks (years, for that matter), I focused on what was working in the story and what needed to be changed. Influenced by my writing class, my previous experiences, my knowledge of story structure, and my Master's thesis (Winters, 2004), I decided that I would think about artforms as a way to edit the story. And so, using different coloured highlighters, I went through the text thinking about drama, visual art, and music. In terms of drama, I thought about the actions and reactions of the characters, how 
the characters would gesture or move, and pictured using my "drama eyes" - what they would look like if they were on stage in front of me (Heathcote, class notes, 2009). On occasion I found myself having to explain my strange call outs (e.g., "Whatever I write you have to do!") and actions (e.g., dragging my hands on the ground) to my 3-year-old son. He would laugh and say, "Mommy's crazy." In addition, I scribbled doodles and words on scraps of paper and post-it notes, trying to capture the next sentence of the story. I also read the story aloud, marking the words that didn't sound right or stood out.

I submitted draft \#10, entitled Jeffery's Wor(I)d Meets Sloth, to my creative writing class, and then later that year (after numerous additional drafts) to Chameleon: UBC's Journal of Writing for Children. This submission was accepted in October of 2003. It was then that I felt the story was good enough. The voices in my head had subsided, "at least for that evening" (Winters \& Hodson, p. 31). I submitted the manuscript on January 1, 2004 as my New Year's Resolution. It was accepted for publication in May of that same year by Maggie de Vries at Orca Book Publishers.

For the next year, I barely heard anything about the book. I forced myself not to edit it again until I heard from Maggie. It was in May of 2005 that I found out that Ben Hodson would be the illustrator. He had recently visited the Orca office; Maggie and the art director were "very impressed with his range, the creativity he brings to his art and the interesting things he does with his lines" (email conversation with Maggie de Vries, May 3, 2005).

A year later I began collecting my edits, emails and a letter from Maggie, and Microsoft Word's "track changes" notes. Most of these edits were text re-phrasings, offered as a way to make the story more concise, visual, active, or rhythmic. For example:

Jeffrey rubbed his eyes. He had just watched his sloth doodle move!

became

“Whoa!" Jeffrey jumped to his feet... (p. 12)

Many of Maggie's suggested edits were to trim the text and to "create slightly more concrete images" (email June 27, 2006). Maggie and I continued back and forth edits such as these, through emails and letters, until November 2006 when I saw the illustrated 
proofs. At this point, with the illustrations articulating the story, Maggie and I felt many of the words were "superfluous" so we included many deletions. As Maggie notes, "...much of the text simply fell away" (de Vries, interview, 2008).

I didn't meet Ben until the book was published in April, 2007. He, Maggie, and I, along with Orca co-publisher Andrew Wooldridge and over 150 audience members, joined together at the Aquarium for the book's launch. ${ }^{1}$

Authorship not only represents the complexities of textual representations and activities through symbolic mediation (semiotic action), it also speaks to people's past experiences and present social worlds (Dyson, 1997; Bakhtin, 1981; Vygotsky, 1979). I label this phenomenon "social (inter)action” and define it as the psychological activities and physical behaviours that people do in order to mediate communication (Harste et al., 1984). I punctuate it with the parentheses to acknowledge the dialogic and reciprocal relationships that enter into every social action. The narrative recount above, which is based on journal entries and class notes, demonstrates some of the complexities of my semiotic actions and social interactions as I authored this book. Conversations in class sparked designs for stories in my mind. These were negotiated on my drive home and produced in words later on my computer. Vygotsky (1979) would argue that all mediation comes from the social ways that people act together. As I began to write Jeffrey and Sloth, I couldn't separate myself from my past experiences; I began negotiating my lived understanding of writer's block, specifically what it felt like to be positioned as a lousy or lazy writer and also as an imaginative storyteller by others. Then after accepting Dr. Leggo's message to "live poetically” and after spotting a sleepy sloth, I began designing a new story in my mind. "Perhaps this sloth could be a match for Jeffrey." I negotiated this idea again and again. Producing while simultaneously re-designing, sharing, re-designing again - it became a quilt of meaning-making. This assembled approach to writing speaks to the importance of redundancies, revisits, and recursive processing in authorship. It was a process that

\footnotetext{
${ }^{1}$ A video of this launch can be found at kariwinters.com/jeffrey .
} 
offered me many opportunities to re/design, re/negotiate, re/produce, and re/disseminate information.

\section{Authorship as Illustrator: Ben Hodson interview}

I met with Ben Hodson after the book launch in April, 2007 to interview him about his process. He had this to say.

$\mathrm{K}$ : Can you tell me about your creative process?

B: Well, it starts once I get the manuscript. I print it out and read it through and try to get with the voice of what the characters are like. And from that, I sort of visualize the surroundings. This book takes place in one room, so that was challenging to try to wrap my head around how to create a narrative in one closed space and keep it interesting and keep it from having too many of the same, repetitive visual places.

But then, so much happens within Jeffrey's own head - there's a lot of that... I know from myself, you imagine things and you kind of blot out your surroundings.... So as I read through the manuscript I try to just visualize what's going on and who the characters are and what voice they have, and from that it kind of gets shaped. You can look through and kind of see how these initial first thoughts of what Jeffrey looks like, kind of this light-bulb head, pretty stylized (see Figures 4.1 and 4.3)

K: His head looks so different. And Sloth looks different too. 
Behind the Scenes

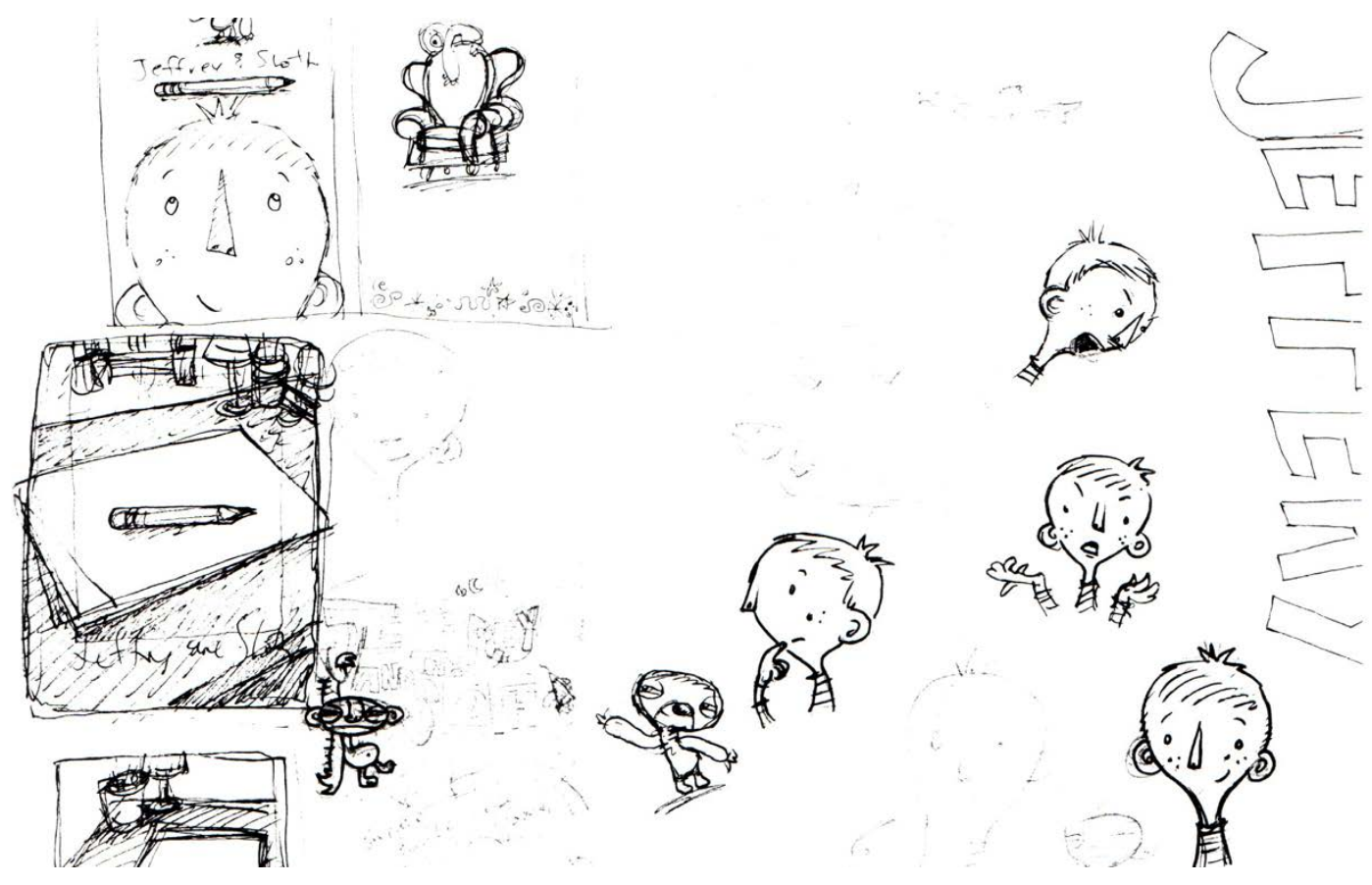

Figure 4.1. Early Sketches of Jeffrey.
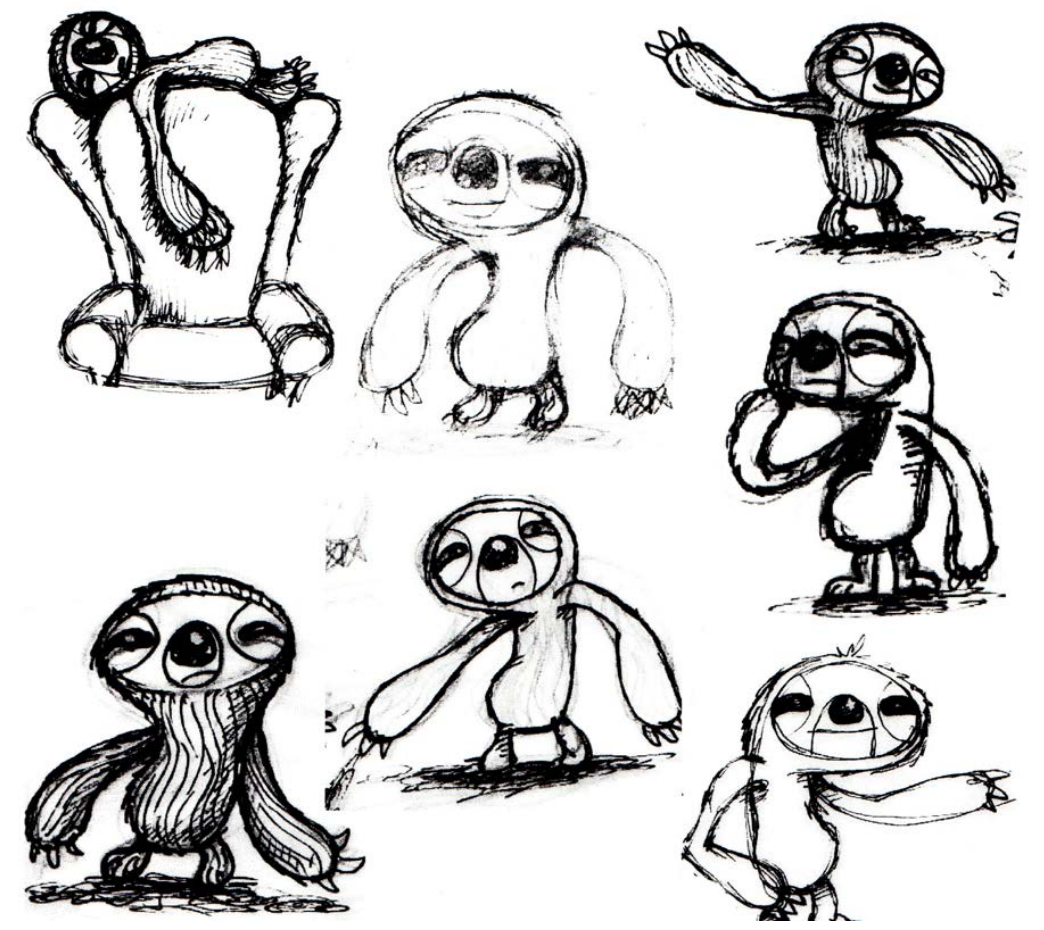

Figure 4.2. Early Sketches of Sloth. 
B: I was thinking about Sesame Street. That whole style of ...

$\mathrm{K}$ : Like their big heads or ...

B: Just, all around. It's not intimidating. Their totally simple face portrays so much nuance to the personality, it's incredible. I loved Sesame Street! I still love Sesame Street. I think it was brilliant.

$\mathrm{K}$ : Did you start drawing right away?

B: My creative process starts with the manuscript. I create images right away from the words. The musicality of them, or how the action is written. I'm also focused on what the characters' surroundings are, and, as corny as it sounds, the feeling of the book. Because the feeling of a book isn't just visual, it's kind of like the words, the tone, the space, the angles - all of it, all mixed together. I think I just really visualize them. I'm a very visual person, so I create imagery right away from the words. The musicality of them, or how they're ... I think I'm more focused on what the surroundings are and mostly the feeling of the book. Because the feeling isn't visual, but still it's kind of like... [pauses to think]

$\mathrm{K}$ : The tone?

B: Yeah. The tone. So then I try to sketch some quick thumbnails to get down some ideas of what comes to my mind instantly when I'm reading. It isn't until the second or third readthrough that I think about [pauses] the era or just the look.

[both look at sketches]

B: ...some different manuscripts have different styles that pop to my mind of either the era or just the look. These different things that change the art, so this [manuscript] kind of had, for me this 50 s sort of, pretty graphic looking -

K: Do you actually research items from that era, like furniture and stuff?

B: Yeah, a lot of eras, all kinds of stuff. I like the really flat look of the 50 s illustration... I just sort of worked for what I was thinking. Fairly flat, kind of angular, graphic colours, big segments of colours... Then, I get some thumbnails down, I start building personalities of 
the characters. I'm reading and drawing and I scribble down stuff... I try to get ideas right away that pop into my mind. Sometimes you forget stuff, you know, you're reading through and you get a flash and you read on and you forget. So it's nice, as soon as you can capture something I find that it's ... sometimes those rough drawings have a lot more life than things you think about too much, things that just come to you. And that's about it. That's the process that I go through.

Design initiates thinking; it is a semiotic action "that stands midway between content and expression” (Kress and Van Leewen, 2001, p. 5). Designs, they argue, are a means to realize discourses in the context of a given communicative situation. Here, authors employ semiotic modes which are capable of being realized. As these researchers argue, there is often "a deliberateness about choosing the modes of representation, and about framing that representation...” (p. 45). As Ben Hodson read the story, he began designing pictures in his mind - the tone of the book, what the surroundings might look like, who the characters might resemble. At the same time, he negotiated his own social experiences, combining bits from different television shows that he has watched and historical eras that he has explored.

Kress and Van Leeuwen (2001) say that sometimes the boundaries between design and production and the boundaries between semiotic resources get blurred. For example, teachers at the front of their class both produce and plan their lessons simultaneously. A vignette demonstrates this idea. While Ben was producing thumbnail sketches based on the look of Sesame Street characters, he drew Jeffrey with a longer and differently shaped head. While in the process of producing this sketch, he realized that the "light-bulb" shaped head (see Figures 4.1 and 4.3) might suggest to readers that Jeffrey was older than the 7 or 8 year-old Ben wanted him to look. For this reason, he decided to re-sketch Jeffrey with a more "melon-shaped head" (see Figures 4.4 and 4.8). Ben positioned himself both as an illustrator and as a reader — “one reader among many” — asking himself how would others understand his work (Chambers, 1985, p. 93). This depth of negotiation could have occurred if design was not entangled with production. He demonstrates that authors move fluidly and in non-linear ways through social (inter)actions. 
Behind the Scenes

\section{Authorship as Editor: Maggie de Vries interview}

Maggie de Vries was the editor at Orca Book Publishers at this time. She had this to say: M: [looks at the original manuscript]... I guess the thing that was striking about this story, in terms of illustration, was the contrast between what was really happening and what the doodles, and how to bring the fantasy and the reality together, and how to have that link be through doodles. And so I was picturing that, and Lynn (the art director) was picturing that. She pictures things in a different way than how I do, she's better at selecting illustrators. Anyway she came up with Ben Hodson.

$\mathrm{K}$ : Can you tell me about your process?

M: When looking at a picture book, I don't always necessarily vividly picture exactly what the illustrations would look like, there's quite a lot of flexibility in my mind, but there is a sense of the story being illustratable, and in need of illustrations to be a complete. Some stories are really evocative. But they just don't need to be illustrated because the pictures are there already - it's all going on in your head. For a picture book, the story has to beg for illustration, and I have to see those gaps. Because I'm very open to a variety of styles, I depend on an art director to bring me samples of different styles so that I can look through and see which ones seem to match what I imagine. And [when I read a story] I'm also looking for what has to happen - it has to be exciting to visualize it.

[M. flips through the pages of the manuscript]

This story in a sense is all set in the same place, but the imagination takes it all over the world, so it works really well that way. And the illustrator handled that really well.

K: These are Ben's initial sketches. (Kari pulls out the dummy layout of Jeffrey and Sloth, see Figure 4.3). 


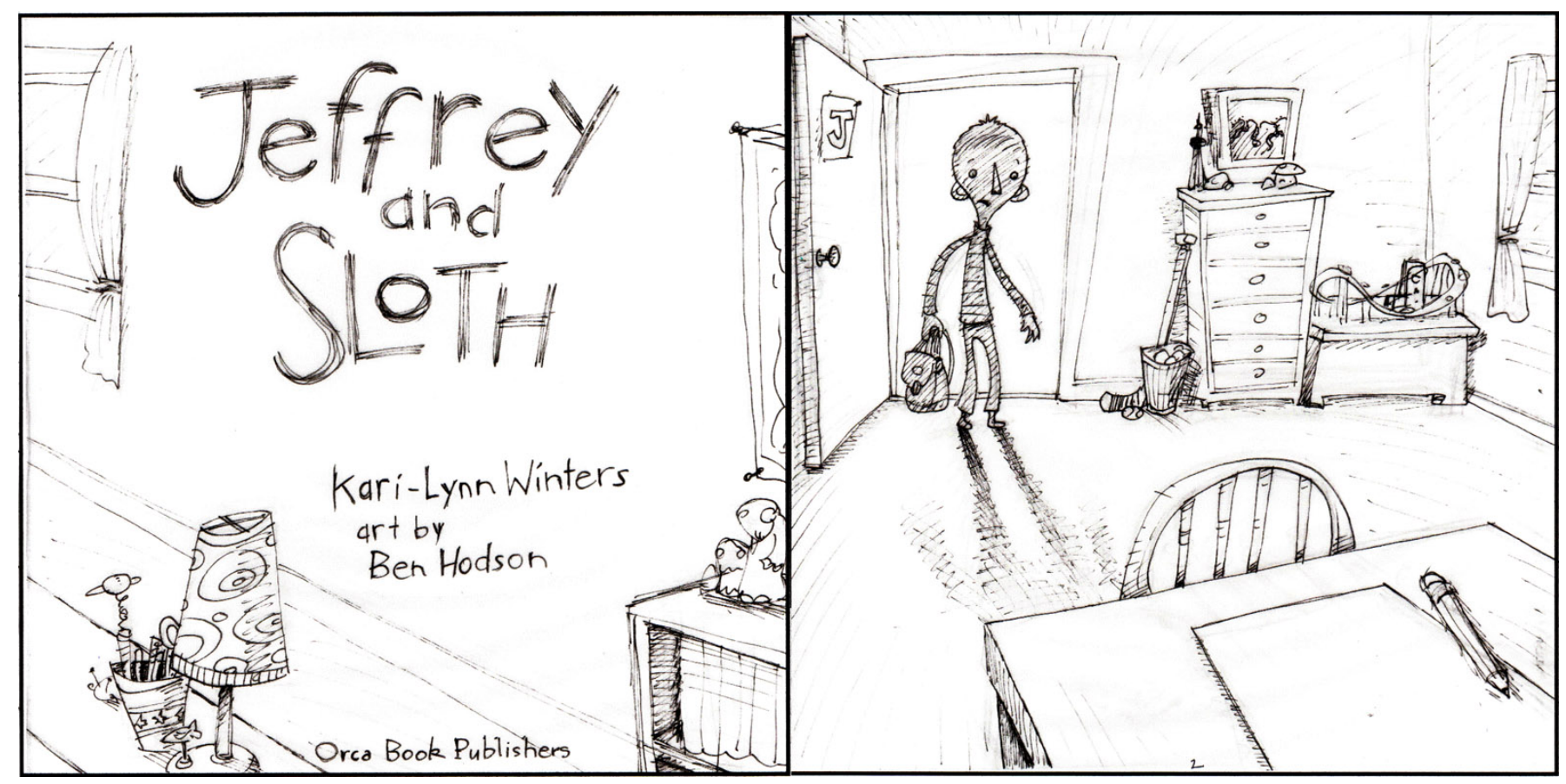

Figure 4.3. Dummy Layout of Jeffrey and Sloth.

M: Yeah, a lot of what's in the finished book is right here already. The style didn't change that much, and a lot of the content stays the same. It's really interesting to see ... So what happened here, is that I'm responding to the first stage, I think. These cuts are [pauses] where the text starts to fall away and become redundant, just bits of it. Pretty minimal edits, it seems to me, just a few cuts... This book was fairly straightforward.

$\mathrm{K}$ : What's going on in your mind as you make these cuts?

M: It's partly that I'm picturing in my mind, as I read, and then sometimes what happens is I'm reading somebody's story and all of a sudden the picture goes fuzzy. I think, and I can't see it. So the picture goes fuzzy, and then I ask the author to bring it into focus - like the details.

$\mathrm{K}$ : It's almost like you're behind a camera or something.

M: Yeah, I'm looking, as I read. Just looking, I don't think about what I'm doing. I just do it. But that is what I'm doing; I'm picturing it. And then there's some bits, when you read a book and there's foreground and background, you know, there's supporting information and information that's central. That's good too. You don't want it all to be foregrounded. You 
Behind the Scenes

want those layers, and so sometimes it's OK to have that bit be blurry in the background.

[Reads]

Here, you say "Now Jeffrey was smiling" - that's foregrounded and you want the reader to see it really clearly. A lot of that is very subtle. I'm not necessarily thinking it out to myself, I'm just sensing my way through and making the suggestions where they feel necessary. And earlier you mentioned music and rhythm, I'm also feeling the, the rhythm of it, the language, and the sound of the language. I find when I read aloud I tend to tap my foot. There's a rhythm. Like when I read aloud, in front of an audience or whatever, my foot is going to find the rhythm. And when I'm editing, I'm still hearing it in my head. And you can sense, as soon as the rhythm isn't working; it starts to bother you. Even if you're just reading a book for fun or whatever - like rhyme, unintentional rhyme, or alliteration. Those kind of things also jump out, so I'm listening to what it sounds like. I'm hearing it in my head.

K: Right.

M: So there's the picture, what you're seeing, there's the rhythm, what you're sensing, there's the actual sound of the words, which is different from the rhythm, which would pick up on any internal rhyme - just word clunkiness that doesn't sound good together. There's also pacing, like for example a sentence I just looked at from what I was just reading, it had the first part of the sentence and then a dash and then the second part but a whole shift in thinking had gone on between the two so just put a period and a capital letter between the two, there's more time for thinking for that to happen. So just subtleties of pacing. I guess that's another part, is questioning. Picturing what's happening, including the action obviously, and not only seeing where it needs to come into focus but also seeing where it doesn't make sense, where I don't believe it, where I don't find the words coming out of the mouth of a particular character are suited to that character, where the characters start talking to feed information to the reader and it stops being the real deal, all those things. So I watch and listen too, it all blurs together....

Maggie de Vries, like myself and Ben Hodson, articulated a sophisticated assemblage of semiotic (inter)actions. In addition to designing and negotiating an array of semiotic resources 
(words, pictures, layouts, rhymes, rhythms, pacing), she also produced and disseminated carefully constructed notes. These notes, when with myself, Ben Hodson, and (at times) the other staff at Orca, needed to be clear enough to decipher. Therefore, there was the added social action of dissemination, as she shared her interpretations and suggested modifications. Not only was Maggie de Vries designing the story and pictures in her own mind, negotiating the relationships of the characters and the semiotic resources in order to produce a tightly-knit plot, she was also designing, negotiating, producing, and disseminating editorial notes for others to read. Here, Maggie assumed the positions of a reader, an editor, and a writer. In addition to interpreting the scenes, picturing the story and identifying the "fuzzy" bits, she also contributed her own ideas and revisions to the story.

\section{Product Assemblages}

Another aspect of the authorship is the product that is left behind. ${ }^{2}$ Below is a double-page spread (pp. 20-21) from the book (Figure 4.4). The most visible authors involved in making this spread are the writer and illustrator, myself and Ben Hodson. However, other, more hidden participants were also involved, including the editor, the art directors, the staff at Orca Book Publishers, picture book critics and reviewers, and the readers.

One might argue that the difference between the "declared" authors (myself and Ben) and the "hidden" or "withdrawn" authors, is that the declared authors produced the initial, original meaning for the picture book (Barthes, 1977, p. 110). However, theorists such as Barthes (1977) and Bakhtin (1981; 1986) suggest that every product of authorship is, in actuality, re-authorship. Barthes (1977) writes:

A text is a multidimensional space in which a variety of writings, none of them original, blend and clash. The text is the tissue of quotations... The writer can only

\footnotetext{
${ }^{2}$ Due to the length of this chapter, I am only able to analyze one double-page spread.
} 
imitate a gesture that is always anterior, never original. His only power is to mix writings... (p. 146)

In this way, everyone who contributes to the picture book, even the writer and the illustrator of the story, are assembling their own meanings based on their dialogic experiences, their cultures, their ideologies, and so forth. All authorship is assembled.

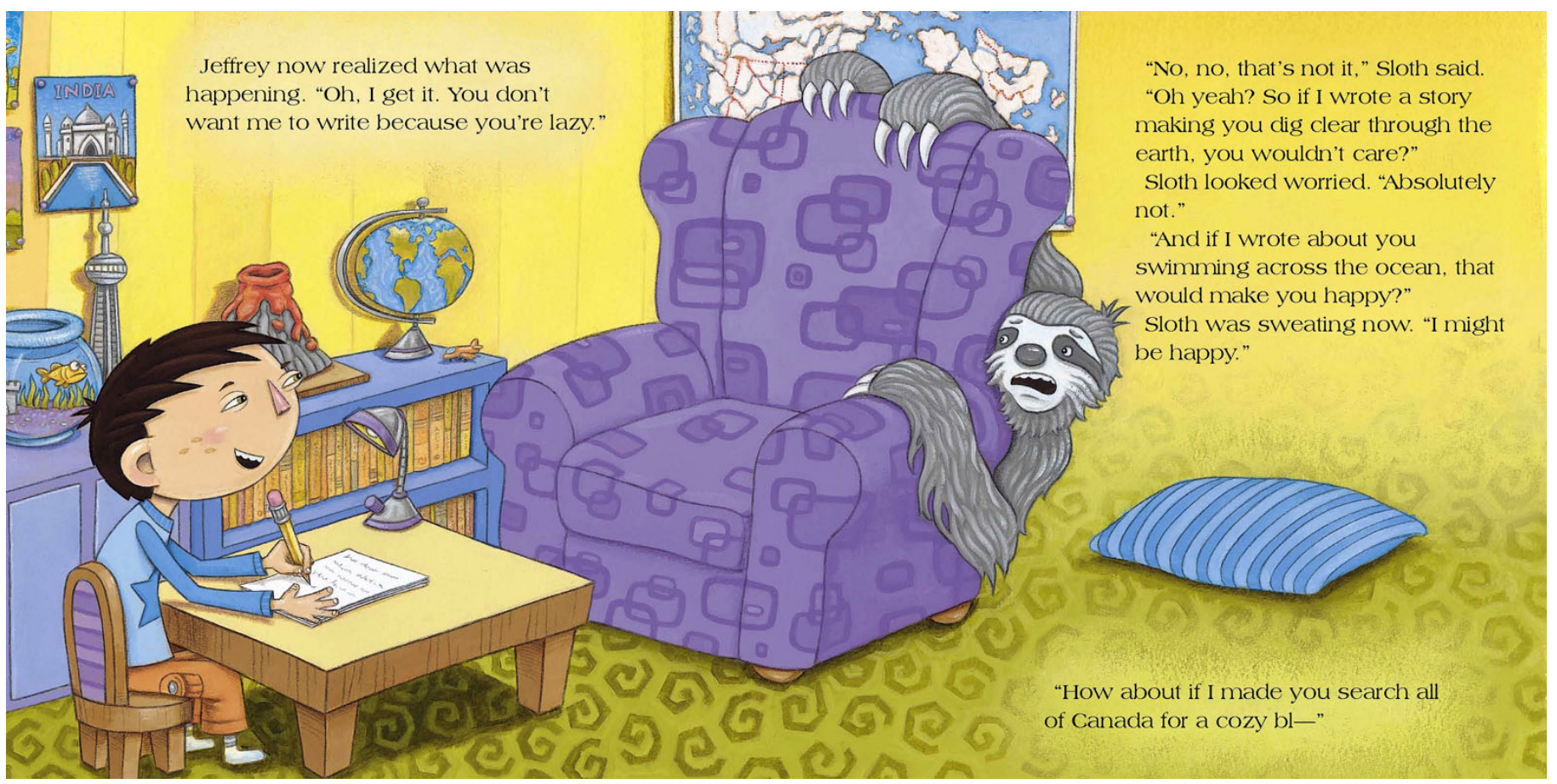

Figure 4.4. Final Layout of Jeffrey and Sloth: pages 20-21.

Some multimodal researchers, based on the work of Vygotsky (1978), have suggested that authors use symbols to mediate their thoughts within sociocultural frames (e.g., Dyson, 1997; Harste et al., 1984). For example, a writer for children may think through a problem on paper, on a screen, while driving, or during conversations through drawings, gestures, conversing, and so forth. These semiotic resources become complexly interwoven together and meshed within the writer's social world and within the writing itself. Thus, as authors externalize meanings, they are also mediating their understandings. 
A multitude of semiotic resources are being mediated in the above spread. Rhythms are afforded through the interweaving questions and statements, as well as through the patterning on the rug and chair. The theatrical nature of the action/reaction dialogue offers a feeling of interrogation and a shifting of character perspectives. The layout, which emphasizes a pause before "How about if I made you search all of Canada for a cozy —,", when combined with Jeffrey’s facial expression, indicate how much Jeffrey is enjoying his new-found power. The use of punctuation, particularly the dash at the bottom of the page, shows that Sloth is interrupting Jeffrey. Sloth’s facial expressions interwoven with his gestures demonstrates Sloth's reluctance, as well as the irony of Sloth’s words “Absolutely not” or "I might be happy.” In addition, the use of the bold colours, angular shapes, and a graphic style of illustration are suggestive of a 1950s time period. This evokes Harste et al.: “[Authorship, then,] is not print production per se, but rather, an orchestrated set of multimodal cues carefully laid forth in an attempt to placehold and potentially sign one’s meaning” (Harste et al., p. 35).

Each semiotic resource mentioned above carries its own communicative meaning potential (Jewitt \& Kress, 2003). These meanings interact with or play off one another, interanimating and mutually inspiring one another, resulting in a totality of meaning that is greater than the sum of its parts. For example, Sloth’s facial expressions, gestures, and physiological responses indicate that he is feeling uneasy. These resources also become entangled with the authors' social (inter)actions. For instance, some children who have read the book tell me that Sloth looks scared; others suggest that he is nervous. Readers fill in the gaps, contributing to and construing their own understandings, thereby becoming authors themselves. Depending on their prior experiences, cultural backgrounds, relationships with writing, understandings of gaze and facial expressions, etc., the moment where the pictorial, linguistic, and theatrical modes combine communicates a particular message to one person (Sloth is scared) and something entirely different to another person (Sloth is nervous). This is because they come to the book's semiotic resources with different understandings of these resources and with unique sets of social 
practices. Then, drawing on their own repertoires of social practices, meaning-making processes, and so forth, each author designs, negotiates, produces, and/or disseminates new meanings for the narrative. Collections of semiotic resources become layered and embedded with the author's social actions in something I call an assemblage. This assemblage is intrinsically multimodally and socially complex, and is always larger than its parts.

As a way to demonstrate some of the ways that Ben and I assembled the semiotic resources and social (inter)actions in this story, I offer an early draft of the story and a section from Ben's interview, followed by a brief explanation of the discursive events.

\section{An Early draft of Jeffrey and Sloth}

Jeffrey now realized what was happening. "Oh I get it. You don't want me to write because you're lazy. Whatever I write you have to do."

"No, no, that's not it," Sloth muttered as he peeked out from behind the chair.

"Oh yeah? So if I wrote a story making you dig clear through the earth, you wouldn't care?" asked Jeffrey.

Sloth looked worried. "Absolutely not." Sloth glanced around, still searching for the blanket.

"And if I wrote about you swimming across the ocean, that would make you happy?"

Jeffrey noticed that Sloth was nervous, but persisted nonetheless. "How about if I made you search all of Canada for a cozy bl..." 


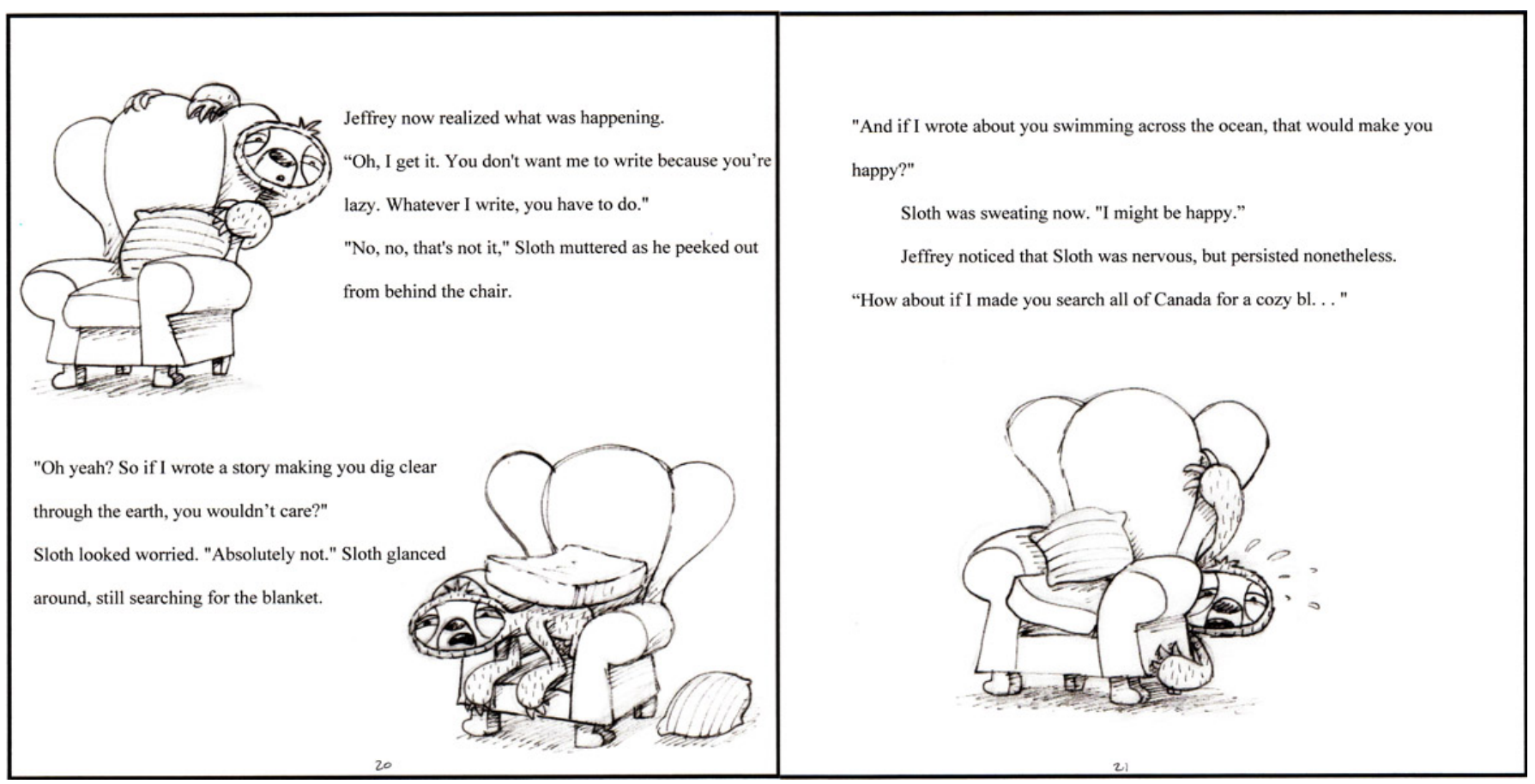

Figure 4.5. Early Draft Layout of Jeffrey and Sloth: pages 20-21.

Here, Ben Hodson and I both performed social (inter)actions while positioning one another. For example, by writing the words "Sloth muttered as he peeked out from behind the chair," I ensured that the chair would be central in the picture. Additionally, at the end of this page I introduced the idea of Canada. These words put the illustrator in a position where he needed to think about how notions of Canada might enter into the story. Although Canada is not in the illustration yet, his stream of consciousness notes at the bottom of the page (too light to be visible in the scans above) read "animated. add bits of things. says Canada" and "Jeffrey sees globe. Sloth globe. everyone sees globe." Hodson is negotiating both Jeffrey’s character (what could make Jeffrey think about Canada at that moment in time with Sloth?) and also his audience (how could he represent Canada to the readers of the book?). About this spread he comments:

I don't just draw the characters and the settings straight on. A lot of times I try to frame it [the spread] too. [This framing] encloses the perspective. It's like a movie, I guess, you're trying to frame what's important and just cut away the clutter. Of course I have to draw the characters and the chair and the pillow because they are in the story itself. But sometimes, 
Behind the Scenes

I draw a lot more [stuff in the room] than I need to and you can just like focus in, zoom in on the room and cut away a lot of the extraneous stuff that's just distracting.

As a writer, I also frame the story. Sometimes I try to envision the story as a play, occurring on a stage. I construe the action and the dialogue in my mind's eye as though the characters are actually moving and talking on stage in front of me. I should note that I never had the opportunity to see Hodson's early illustrations (Figure 4.5); the earliest draft I saw was much more similar to the final version:

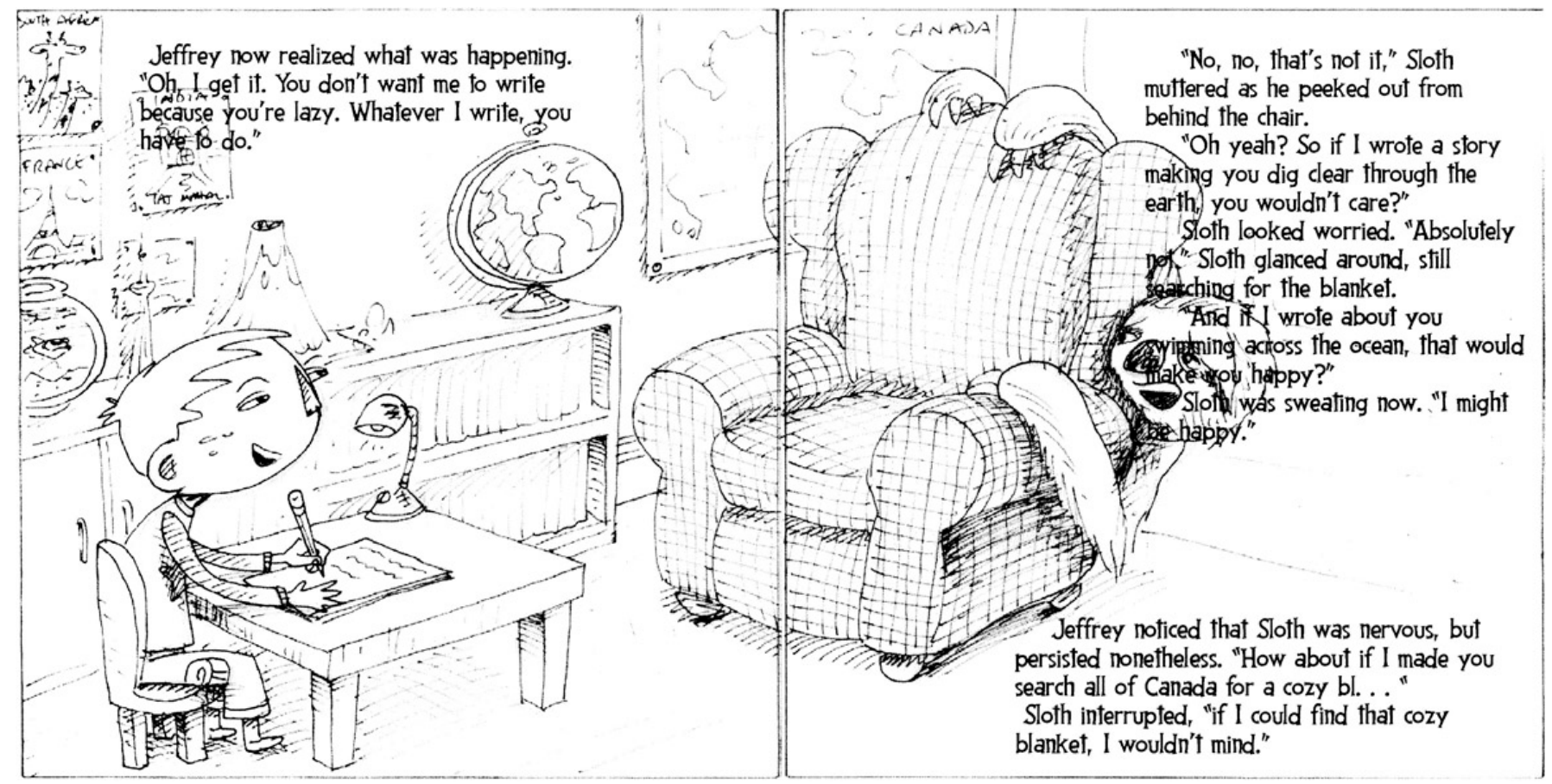

Figure 4.6. Final Draft Layout of Jeffrey and Sloth.

It is clear there were too many words on this spread, making it look cluttered and unappealing to a reader. By re-drawing the illustration in this way, Hodson positioned me as an editor — what words could I take out to make the spread look less cluttered? And I was positioned as an art director and marketer: will the extra words clutter the page layout? Will readers enjoy the experience? Since Hodson had drawn the chair with Sloth behind it, I could now take out the unnecessary words that re-articulated the same meanings. In terms of structured 
routines, it is typical for a writer to include too many details — this is because authors and illustrators do not often have the opportunity to meet and discuss their visions of the story. Additionally, it is not considered good form for an author to give an illustrator too many notes about how she wants the spread to look. Therefore, in order to ensure that the picture included the degree of irony that I wanted for the story, I needed to write words like: "Sloth muttered as he peeked out from behind the chair" or "Sloth was sweating now."

Regarding these pages, Maggie de Vries interacted with me in other ways. For example, she suggested that I remove the phrase "And whatever I write, you have to do.” As the editor, she was eligible to make suggestions such as these. Her suggestion positioned me as a critic and a reader — would this decision make the book more engaging? And it positioned me as a teacher — taking out this phrase might allow the children to make more inferences. In the end this was a good decision as the phrase was telling, not showing, the reader what to think.

As editor, de Vries is also eligible to decide on the page breaks. She states:

I go through the book and start breaking it up. Places where it seems like a good idea to break it up, for a set of reasons which are usually not articulated fully in my mind. And then I get to the end and I've got way too many pages, usually. Or sometimes it's just one or two too many. And then I go back and look for ways of combining in order to get it into 32 pages. So I kind of feel my way through, but what I'm looking for is natural breaks in the action. I'm looking for moments of surprise, where a page break can heighten that. Page breaks are a little bit like chapters; in a sense, they can be. They can be used as cliffhangers, in a sense. (Interview transcript, 2008)

From a reader's perspective, too many words might make a page look cluttered. Too few words might not carry enough of the action. Consciously thinking about the page numbers in this way situated de Vries as a page designer; not only was she estimating how many words should go on any one page, she was also figuring out the number of page layouts needed across the entire book. While the standard length for a picture book is 32 pages (Pattison, 2008), there is more 
than one way to break up the content into those 32 pages (Martz, 2009). De Vries elaborates on how she decides on the page layouts:

And then I'm thinking about how to end it. And there's the choice of ending it on page 32, which gives you a single page. This has a different impact. So a reader's going through spread, spread, spread, spread, and then often there's a little surprise at the end of a picture book, and that can be really effective on page 32. In this book we used the opening to make an impact - the half and full titles are leading the reader in. They lead us in. (Maggie flips through the beginning pages of the book.) There is the blank page [the half title - see Figure 4.7.], and there is Jeffrey looking at the page [the full title — see Figure 4.8], and then into the story... I think it was probably the right decision. I think the opening's very effective.

Readers often comment on half title (showing the blank page; see Figure 4.7) and the full page title (showing Jeffrey standing at the door, ready to enter his room; see Figure 4.8). These pages introduce the problem and Jeffrey's character. They also add to the tone of the entire book.

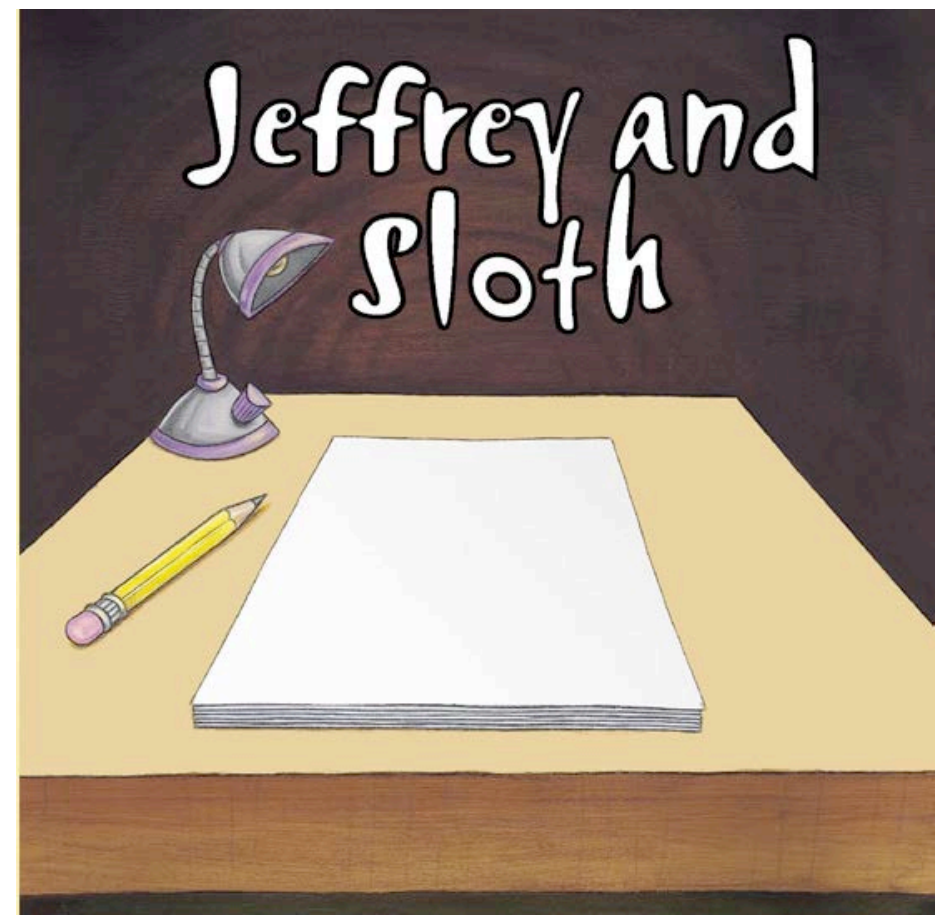

Figure 4.7. Final Layout of Jeffrey and Sloth: Half Title page. 


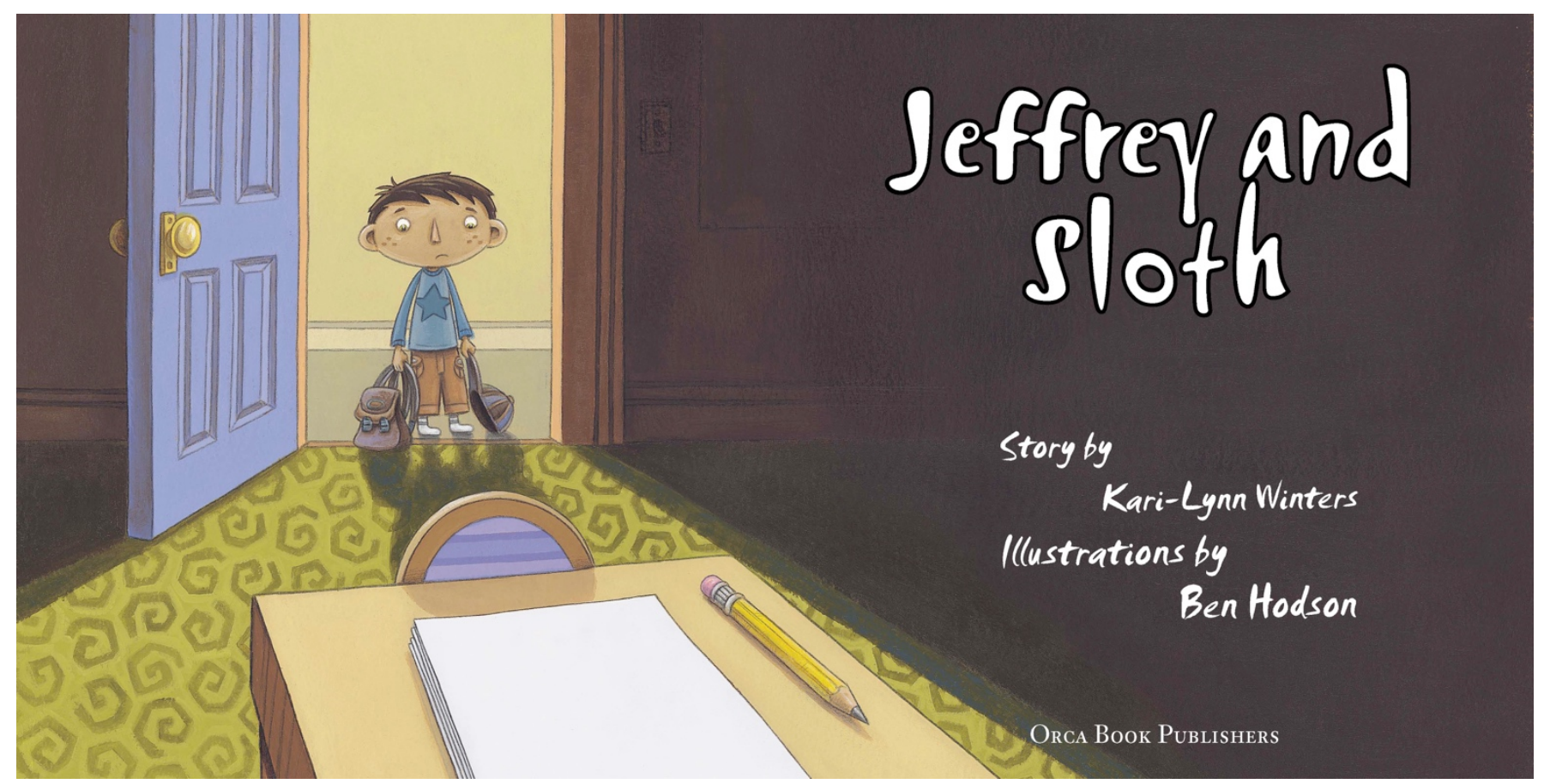

Figure 4.8. Final Layout of Jeffrey and Sloth: Full Title page.

\section{Authorship as Assemblage}

Throughout the chapter I refer to Ben Hodson (illustrator), Maggie de Vries (editor) and myself (Kari-Lynn Winters, writer) as authors of the book Jeffrey and Sloth. ${ }^{3}$ Authorship goes beyond language alone. We were all authors, donating meaning. We originated this combination of language, but also designed and created the pictures, proofread and made modifications to the pacing, the rhythms, the narrative, and we interpreted the story. For this reason, I define "author" not only as the person who writes the words, but any person/people who donates to originate/s, re-construct/s or animate/s - a piece of work. Much like with copyright law, in this chapter an author is defined as the creator/recreator (any person or group) of any work, be it written, painted, sculpted, filmed, photographed or otherwise, within a network of social, dialogical practices, who designs (originates), negotiates (interprets), produces (represents), or

\footnotetext{
${ }^{3}$ Although I also consider Doug McCaffry (book designer) another author in the Jeffrey and Sloth project, I was unable to speak with him as he is no longer working at Orca Book Publishers.
} 
disseminates (communicates) meaning. ${ }^{4}$ Drawing on the work of Roland Barthes (1977), notions of authorship suggest that in practice there are no simple producers versus simple consumers of texts; these roles are intrinsically connected and interwoven. This idea also resonates with Barthes’ earlier work (1970), specifically his essay S/Z:

Our literature is characterized by the pitiless divorce which the literary institution maintains between the producer of the text and its user, between its owner and its consumer, between its author and its reader. This reader is thereby plunged into a kind of idleness — he is intransitive; he is, in short, serious: instead of functioning himself, instead of gaining access to the magic of the signifier, to the pleasure of writing, he is left with no more than the poor freedom either to accept or reject the text: reading is nothing more than a referendum. (p. 4)

Understanding authorship in these broader ways means that an author can be someone who interprets a book or someone who actualizes it, including a children's book writer, an illustrator, an editor, a reader, an actor, a playwright, a musician, and dozens of other roles. These authors can be, as Barthes (1977) states, “declared, hidden, or withdrawn” (p. 111).

Researchers such as Marjorie Siegel (1995; 2006) posit that authors move between multiple modes to mediate their understandings. Siegel, drawing on Suhor (1984), defines transmediation as the process of taking understandings from one sign system and moving them into another in order to make meaning. In this way, authors have additional opportunities to engage with texts and to realise information in generative and reflective ways (p. 456). Hodson's quote at the beginning of this chapter demonstrates an array of modes that he is transmediating between. He moves from reading the language, to hearing the tone of the manuscript, to drawing sketches, and so forth. As Sipe (1998) notes, Siegel's ideas are useful when thinking about the

\footnotetext{
${ }^{4}$ http://strategis.ic.gc.ca/sc_mrksv/cipo/cp/copy_gd_protect-e.html
} 
authorship of picture books, because authors do transmediate between a range of modes as they interpret and realize meaning.

I wonder, though, if this idea could be further extended? In this case study the authors demonstrate their use of modes (e.g., writing, illustrating, critiquing, reading) and semiotic resources (e.g., actions, rhythms, colours, angles, and so forth). Indeed, an orchestration of semiotic resources, social (inter)actions, and subject positions are realized here and assembled during the acts of multimodal authorship. The resources that authors employ hold their own meaning potentials that suggest storylines and position other authors in sophisticated and productive ways. Drawing on this case, I posit that within situational contexts authors use and orchestrate a multiplicity of modes and semiotic resources. For instance, each of the authors above uses and revisits the musical mode: while I address the cadence of the language, Hodson speaks of the tone or feel of the book, and de Vries discusses the rhythm that people sense. There is no denying that in musical semiotic systems, structures of rhythm, melody, salience, and framing matter; they are used and combined to construe distinct meanings (Van Leeuwen, 2005). For children's picture book authors, using the mode of music is invaluable. Picture books are intended to be read aloud. The musicality of the language (e.g. use of syntax, diction, punctuation, the flow) and the pictures need to simultaneously radiate both the energy and the intent of the story. The musical mode is a force that moves the reader fluidly through the book. The musicality of the language can either enhance or distract from the message that the author is trying to convey. For this reason it is a crucial part of writing picture books; the words need to fit together much as lyrics in a song. They need to flow off the tongue, and to sound right. Creating a synergy of modes that goes beyond the words and the illustrations (e.g., thinking about the musical mode) reveals an additional acoustic layer of information - here the picture book also shapes meaning through the semiotic resources of sound and silence.

Additionally, authors continually shift between the social (inter)actions of design, negotiation, production, and dissemination as they donate meaning, and they situate themselves 
and others within that practice.

Multimodal research on children's literature usually has asked questions like: "What modes of meaning-making are offered by picture books?" "What do children glean from the ways that the pictures and the images go together?" "What information do the pictures offer that the language may not?” In our modern information economy, where children and adults alike are authoring in a multitude with a multitude of resources and at least four different semiotic actions, it might be more helpful to ask: "How do authors use semiotic resources in social contexts in order to author picture books?” or "What are authors doing with picture books, specifically how are they assembling social (inter)actions and positioning one another in the process?”

\section{Conclusions}

Picture book authorship is dynamic, complex, and dialogic. It goes beyond two modes of meaning-making to incorporate an assortment of semiotic modes and resources such as images, words, punctuation symbols, “digitally-manipulated” layouts, sounds, colours, rhythms, shapes, patterns, page breaks, and so forth. Authors read (interpret) and write (realize) these modes, assembling them and at the same time continually shifting among the social (inter)actions of designing, negotiating, producing, and disseminating meaning.

\section{Acknowledgement}

Kari-Lynn would like to acknowledge the contributions of Ben Hodson, Maggie DeVries, and Orca Book Publishers. Without their support and time, this article would not have been made possible.

Kari-Lynn Winters is an award-winning children's author, scholar, playwright, and performer. Since 2007, she has had more than 25 books published with 4 more in pre-press production. She is also an Associate Professor at Brock University, where she teaches drama-in-education, dancein-education, and language arts to teacher candidates. 
Behind the Scenes

\section{References}

Bakhtin, M. (1981). The dialogic imagination: Four essays. Austin, TX: University of Texas Press.

Bakhtin, M. (1986). Speech genres and other late essays. Austin, TX: University of Texas Press. Baldry, A., \& Thibault, P. (2006). Multimodal transcription and text analysis. London: Equinox.

Barthes, R. (1970). S/Z. New York: Hill and Wang.

Barthes, R. (1977). Image, music, text. London: Fontana.

Chambers, A. (1985). Booktalk: Occasional writing on literature and children. New York: Harper \& Row.

Davies, B., \& Harré, R. (1990). Positioning: The discursive production of selves. Journal for the Theory of Social Behaviour, 20(1), 43-63.

Dyson, A. H. (1997). Writing superheroes: Contemporary childhood, popular culture, and classroom literacy. New York: Teachers College Press.

Hamilton, M. (2000). Expanding the new literacy studies: Using photographs to explore literacy as social practice. In D. Barton, M. Hamilton, \& R. Ivanic (Eds.), Situated literacies: Reading and writing in context (pp. 7-15). New York: Routledge.

Harste, J., Woodward, V., \& Burke, C. (1984). Language stories and literacy lessons. Portsmouth, NH: Heinemann.

Jewitt, C., \& Kress, G. (Eds.) (2003). Multimodal literacy (Vol. 4). New York: Peter Lang.

Kress, G., \& Van Leeuwen, T. (2001). Multimodal discourse: The modes and media of contemporary communication. London: Arnold.

Martz, J. (2009). A second look at picturebook dummies. Retrieved July 2009 from http://drawn.ca/2009/03/09/a-second-look-at-picture-book-dummies

Pattison, D. (2008). Standard picturebooks are 32 pages. Retrieved July 2009 from http://www.darcypattison.com/picture-books/picture-book-standards-32-pages

Siegel, M. (1995). More than words: The generative power of transmediation for learning. Canadian Journal of Education, 84(1), 65-77.

Siegel, M. (2006). Rereading the signs: Multimodal transformations in the field of literacy education. Language Arts, 20(4), 455-475.

Sipe, L. (1998). How picture books work: A semiotically framed theory of text-picture relationships. Children's Literature in Education, 29(2), 97-108.

Suhor, C. (1984). Towards a semiotics-based curriculum. Journal of Curriculum Studies, 16, 247-257.

Van Leeuwen, T. (2005). Introducing social semiotics. London: Routledge.

Vygotsky, L. (1978). Mind and society: The development of higher psychological processes. Cambridge, MA: Harvard University Press.

Winters, K. (2010). Quilts of authorship: A literature review of multimodal assemblage in the field of literacy education. Canadian Journal for New Scholars in Education, 3(1). http://www.cjnse-rcjce.ca/ojs2/index.php/cjnse/article/viewArticle/161

Winters, K., \& Hodson, B. (2007). Jeffrey and Sloth. Victoria, BC: Orca Book Publishers. 


\section{Appendix A: Authorship As Assemblage Analysis Frame}

This analysis frame draws from the work of Barthes (1977); Bakhtin (1981); Kress and Van Leeuwen (2001); Baldry and Thibault (2006); Davies and Harré (1990); and to some extent the work of (Hamilton, 2000).

Each element of the frame is defined below.

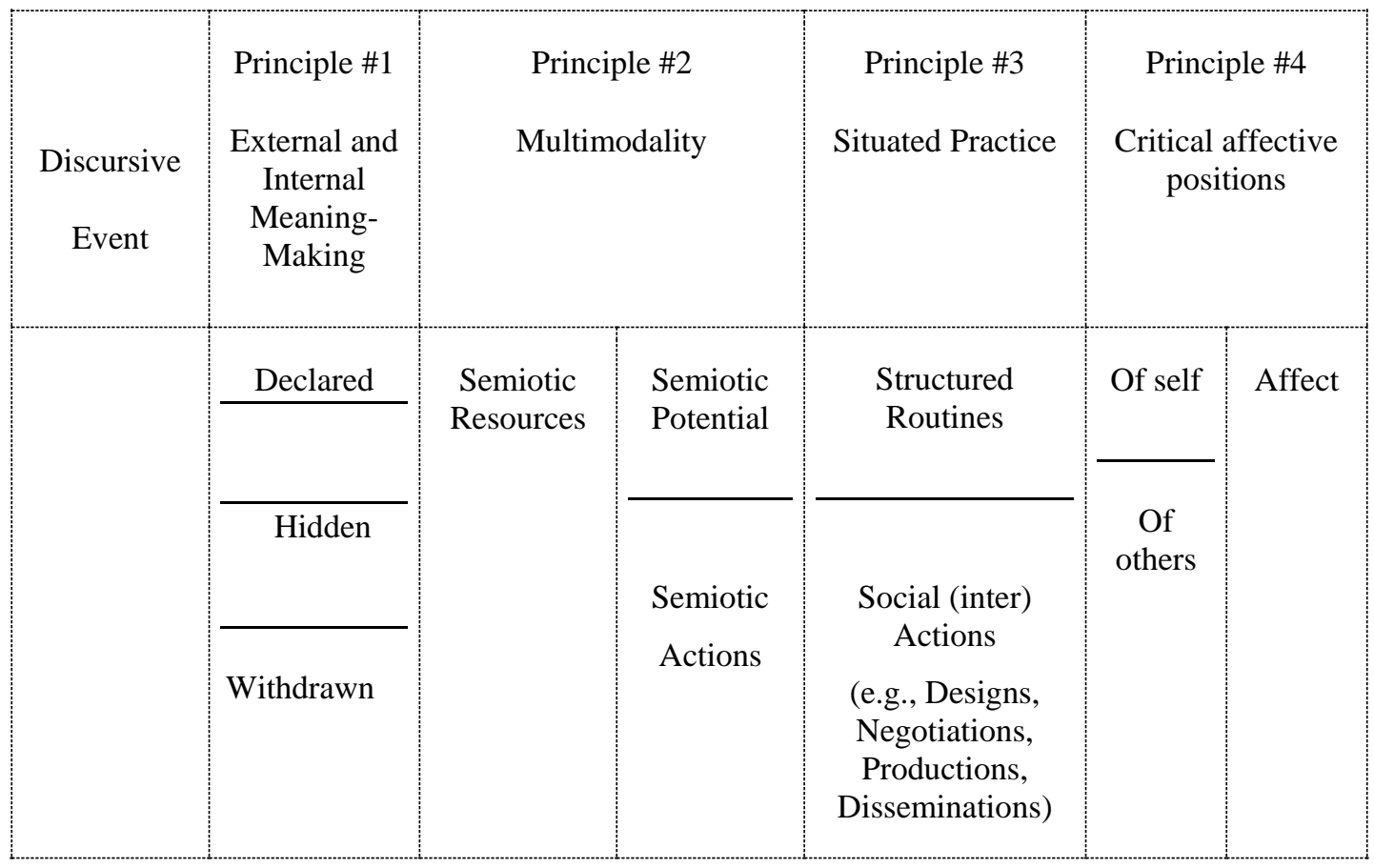

- Discursive Event: any occasion where multimodal discourse is authored/assembled (designed, negotiated, produced, or disseminated) among participants and within concrete situational contexts (Kress \& Van Leeuwen, 2001).

- External and Internal Meaning-Making: Authors make meaning both externally (producing and disseminating) and internally (designing and negotiating): this section describes how the participants "donate” meaning to the texts or storylines that are being created (Barthes, 1977). Meaning contributions apply to both the interpretation and the actualization of meaning.

- Declared Participants: the authors who are visibly creating meaning and contributing to the text within the social contexts (Barthes, 1977), such as the actors who are seen animating the characters on stage or the child who writes a letter at the kitchen table.

- Hidden or Withdrawn Participants: the less visible authors who are or may have been involved in donating meaning and contributing to the text within the social contexts (Barthes, 1977; Kress \& Van Leeuwen, 2001). For example, the audience who interprets the meaning of a play, the playwright or the director who contributed to the play's narrative, or perhaps the people who were once "dialogically" involved in contributing to 
the meaning-making — such as Newton, if the play's topic were to be about gravity (Bakhtin, 1981).

- Semiotic Resources: The orchestrations of semiotic resources within discourses and situated social contexts. More specifically, the semiotic resources function together intersemiotically and intrasemiotically (Baldry \& Thibault, 2006).

- Semiotic Potential: The potential (affordances and limitations) arising from the perceivable properties of a mode or a semiotic resource being used (Kress \& Van Leeuwen, 2001).

- Semiotic Actions: The actions taken, when using semiotic resources.

- Social (inter)actions: the multimodal actions or activities that authors do to construct meaning, including the ways they design, negotiate, produce, and disseminate information within situated contexts. In addition, social (inter)actions include the ways that authors interact with one another, and how their actions relate to the discourses across and within sociocultural contexts (Bakhtin, 1981; Kress \& Van Leeuwen, 2001).

- Positions Self: How, within a discourse, authors psychologically or physically situate themselves (i.e. socially, culturally, economically, politically) in both visible and hidden ways.

- Positions Others: How, within a discourse, authors psychologically or physically situate others (i.e., socially, culturally, economically, politically) in both visible and hidden ways (Davies \& Harré, 1990).

- Affect: The emotional resonance that is either initiated or left behind and is mediated through semiotic potential and social (inter)actions. 